\title{
The role of serotonin and diet in the prevalence of irritable bowel syndrome: a systematic review
}

\author{
Khushi Bruta, Vanshika, Kishnoor Bhasin and Bhawana* (D)
}

\begin{abstract}
Serotonin or 5-hydroxytryptamine (5-HT)- a neurotransmitter of both the Enteric Nervous System and the Central Nervous System is synthesized by the hydroxylation of L- tryptophan to 5-hydroxytryptophan.

Serotonin has been associated with gut functions like assimilation and absorption, alongside the regulation of particle transport and fluid discharge in the gastrointestinal tract and its deficiency is found to be a prominent factor in the prevalence of gut disorders like Irritable Bowel Syndrome.

For this review, we assessed the conventional treatment methods of common drugs, with the recently accredited treatment options like dietary regulation, exercise, meditation, and acupuncture. Having found that the most commonly used drugs exhibited various side effects like nausea, fatigue, rash, and dizziness, an in-depth evaluation of different Indian dietary patterns and their respective effects on tryptophan levels has been highlighted to formulate an ideal diet for patients with Irritable Bowel Syndrome (IBS). This review seeks to explore the numerous studies conducted to link IBS with the lack of serotonin production in the body, alongside exploring the evidence associating certain foods with raised tryptophan levels to hypothesize a suitable Indian diet.

This review, in its essence, stresses the crucial need for further research on the dietary implications of common Indian foods and their FODMAP (Fermented Oligosaccharides, Disaccharides, Monosaccharides, And Polyols) contents, while underscoring the benefits of using unconventional and natural methods for the treatment of tryptophan-related gut disorders.
\end{abstract}

Keywords: Serotonin, Tryptophan, Irritable bowel syndrome, FODMAP

\section{Background}

Serotonin (5-hydroxytryptamine or 5-HT) is a neurotransmitter associated with the Central Nervous System and the Enteric Nervous System. It is produced by a biochemical conversion process (Fig. 1) where tryptophan, a component of proteins, combines with tryptophan hydroxylase, a chemical reactor to produce 5-hydroxytryptamine [1].

It is usually called the happy hormone because it contributes to wellbeing and happiness. A decrease in its level has been seen in various mental illnesses like depression and anxiety.

\footnotetext{
* Correspondence: bhawana.sharma@rajguru.du.ac.in

Department of Biochemistry, Shaheed Rajguru College of Applied Sciences for Women, University of Delhi, Vasundhara Enclave, New Delhi 110096, India
}

Apart from this, Serotonin has another crucial role in Gut motility. It was established during the early 1950 s that a large amount of Serotonin (5-HT) is released from the mucosa at a comparative time as peristalsis happened within the digestive tract [2]. Since then, numerous studies have been conducted to analyze the relation between 5-HT and motility.

\section{Serotonin and gut}

The microorganisms present in the gut are capable of synthesizing 5 -HT but this bacterial production is far exceeded by biosynthesis in Enterochromaffin (EC) Cells. Alternatively, these microbes help regulate the gut and plasma 5-HT levels by providing signals to the host

(c) The Author(s). 2021 Open Access This article is licensed under a Creative Commons Attribution 4.0 International License, which permits use, sharing, adaptation, distribution and reproduction in any medium or format, as long as you give appropriate credit to the original author(s) and the source, provide a link to the Creative Commons licence, and indicate if changes were made. The images or other third party material in this article are included in the article's Creative Commons licence, unless indicated otherwise in a credit line to the material. If material is not included in the article's Creative Commons licence and your intended use is not permitted by statutory regulation or exceeds the permitted use, you will need to obtain permission directly from the copyright holder. To view a copy of this licence, visit http://creativecommons.org/licenses/by/4.0/. 


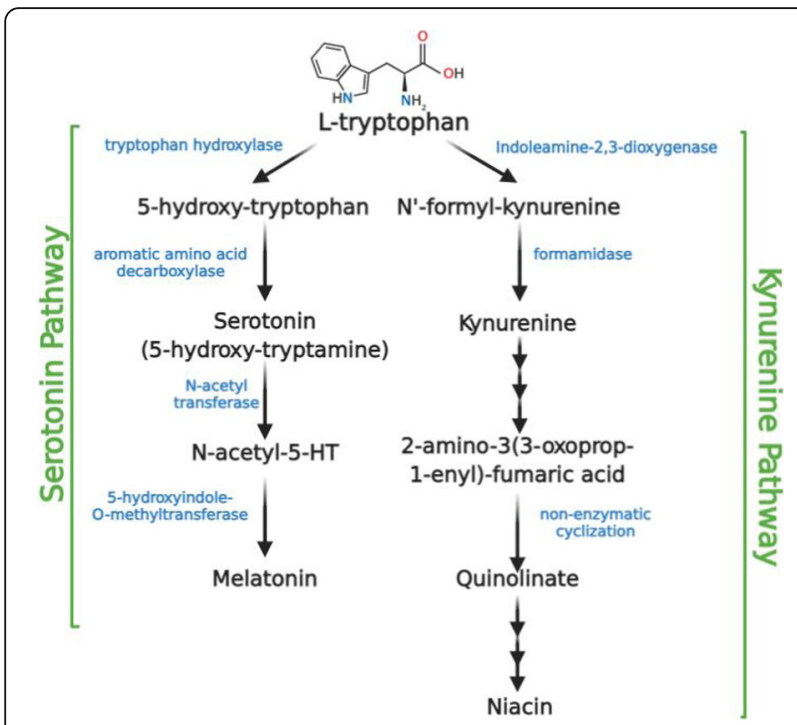

Fig. 1 Tryptophan Metabolism: Tryptophan is a substrate for the large neutral amino-acid transporter system and competes for transport with several other amino acids essential for brain function. Once in the CNS, L-tryptophan is hydroxylated to 5-hydroxytryptophan by the enzyme tryptophan hydroxylase type 2 , the rate-limiting step in the brain serotonin synthesis. This is followed by subsequent decarboxylation involving the enzyme L-aromatic acid decarboxylase to serotonin (5-hydroxytryptamine, 5-HT)

mucosal cells in the form of Tryptophan hydroxylase 1 (TPH1) expression [3]. Moreover, it has been directly affirmed that Enterochromaffin (EC) cells are without a doubt mechanically sensitive and express the mechanosensitive molecule channel. (Fig. 2).

Studies like the Tyrode arrangement, utilizing modified Trendelenburg's strategy were conducted in a confined portion of the lumen to study the role of 5-HT in peristaltic reflex [4-6]. Grider, in 1998, illustrated the part of 5-HT-4 receptor ascending contraction and descendingrelaxation in the jejunum of humans, guinea pigs, and rodents. 5-HT3 has to be included in motility and discharge [7]. Luminal 5-HT is required for intestinal supplement and water assimilation, and impacts bicarbonate and electrolyte discharge into the lumen [8-10]. Through stimulation of 5-HT3 receptors on intestinal vagal afferent nerve endings, EC-cell-derived 5HT increases postprandial pancreatic protein release, synergistically with cholecystokinin [11]. This, in turn, increases absorption and assimilation of additional luminal secretion. Gastrointestinal 5-HT increases bile activity by increasing the expression of the apical sodium-dependent bile salt transporter [12]. As such, 5-HT may act as a referee of several impacts that are credited to both 5-HT and Glucagon-Like Peptide-2, checking restriction of gastric cleansing and nutrient-stimulated gastric release [13-16].

Evidence for direct regulation comes from recent studies on lab-raised and gut microbiome-deficient, germfree animals. They have high levels of circulating tryptophan and lower levels of serotonin but once gut microbes are introduced, falling levels of circulating tryptophan are observed [17].

Fasting also fortifies the synthesis and discharge of 5HT from EC cells in mice due to increased translation of TPH1 [18]. Upon detection of low glucose by colonic EC cells, that mirror in-vitro fasting conditions, an increase in TPH1 expression, and 5-HT production and release are observed [19].

Irritable Bowel Syndrome (IBS) is a chronic gastrointestinal disorder affecting about $9-23 \%$ of the population in the world. It includes a group of symptoms including abdominal pain and changes in the pattern of bowel movements, without any evidence of underlying damage. IBS has been divided into 4 types depending on whether diarrhea, constipation, both, or neither are common (IBS-D, IBS-C, IBS-M, IBS-U). There is no specific laboratory or imaging test that can be helpful in the diagnosis of IBS. Physicians use 3 sets of diagnostic criteria for IBS which are:

1. Rome Criteria: This includes abdominal pain and discomfort lasting on average at least 1 day a week in the last 3 months. Pain and Discomfort are associated with defecation.

2. Manning Criteria: This focus on pain relieved by passing stool and on having incomplete bowel movements, mucus in stool, and changes in stool consistency.

3. Type of IBS: Symptoms according to the type of IBS are observed.

\section{Relationship between serotonin and irritable bowel syndrome}

Numerous studies were done to legitimize the relation of Irritable Bowel Syndrome to the lack of serotonin synthesis and release. Gene knockout and Gene transformation were among the best techniques used to study this relationship. Researchers examined that a decrease in the production of intestinal serotonin leads to the weakening of the intestinal lining, which inevitably results in clogging or constipation and an increment in serotonin levels within the gut [20].

One hypothesis is that the Serotonin TransporterSERT is deficient in the enterocytes of individuals with IBS. Another hypothesis focuses on diminished numbers of enterochromaffin cells within the GI tract of individuals with IBS.

It was shown that the upregulation of the Indoleaminepyrrole 2,3-dioxygenase activates a metabolic pathway, which is also likely to be associated with the pathogenesis of IBS. Afterward, considerations have shown that both females [21] and males [22] with IBS have extended kynurenine concentrations compared to controls. Therefore, 


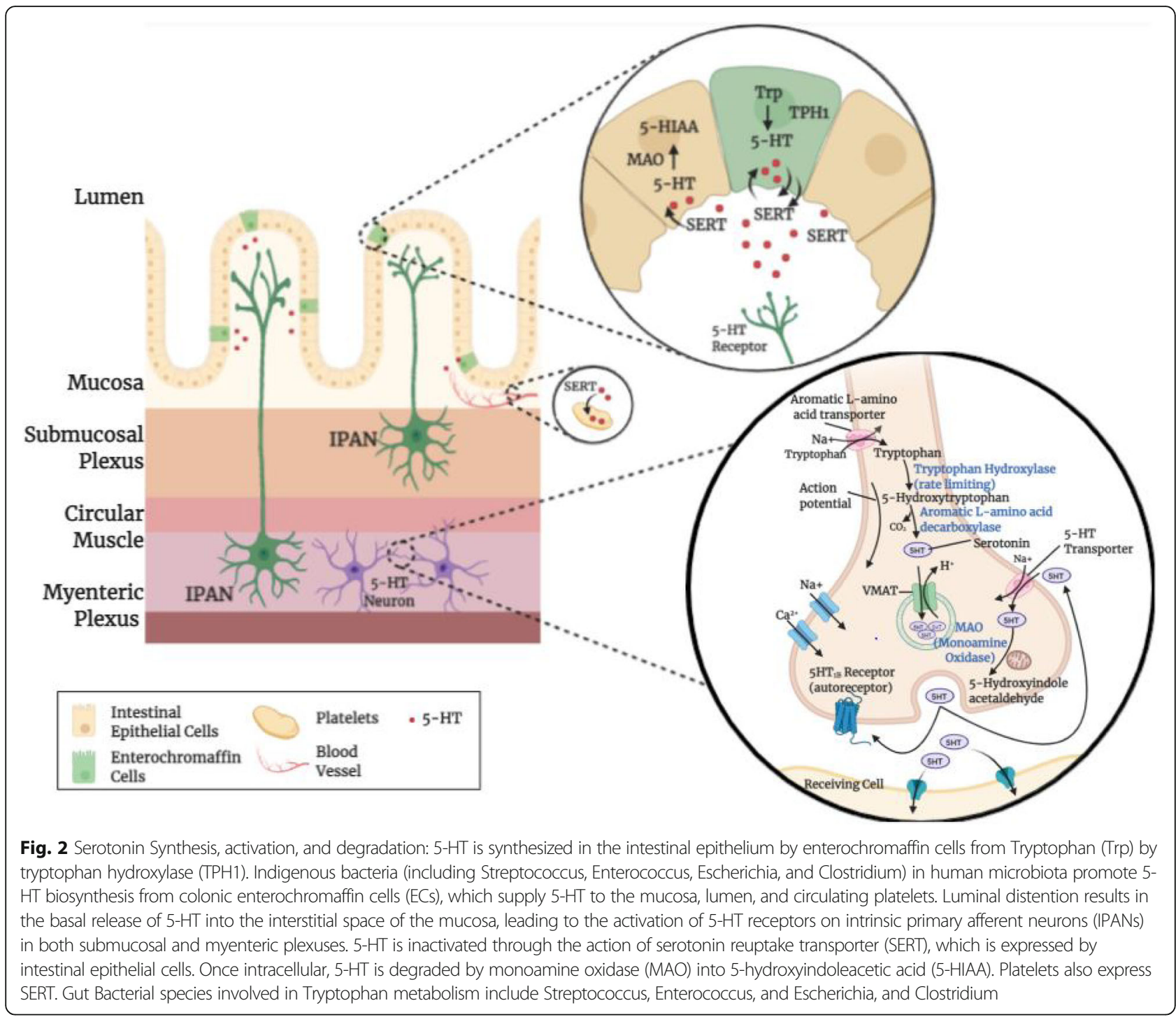

a positive relationship was found between IBS and the kynurenine/tryptophan extent. Those with extraordinary IBS side impacts have extended shunting of tryptophan along the kynurenine pathway which contributes to the unusual serotonergic function. SERT expression is seen to be diminished in IBS patients [23]. On the other hand, SSRI administration increases colonic motility and highamplitude compressions are related to stomach cramping [24]. Chronic treatment of mice with the specific serotonin reuptake inhibitor (SSRI) paroxetine, reduced stool yield, and delayed upper GI tract movement [25]. These discoveries propose that changed mucosal 5-HT signaling seems to contribute to the indications of IBS.

\section{IBS and its subtypes}

There are three major subtypes of IBS. IBS-D is associated primarily with diarrhea, IBS-C is concerned with constipation and lastly, the third subtype deals with mixed symptoms of both constipation and diarrhea There have been studies that were conducted to compare the SERT-P polymorphism in IBS patients and sound individuals. This polymorphism comes about in a long $(\mathrm{L})$ and a brief $(\mathrm{S})$ allele. It can occur as homozygous (S/S) genotypes, heterozygous (L/S) SERT genotypes, and homozygous long (L/L) genotypes.

This study demonstrated that the SERT-P polymorphism was related to IBS-C within the Indian populace. The recurrence of the SERT-P S/S genotype was higher in IBS-C patients than in normal individuals [26].

In IBS-D, there has been no identified distinction in the basal or fortified mucosal 5-HT release, despite the finding that both mucosal 5-HT secretion and $\mathrm{TpH} 1$ mRNA levels are declined [27]. Postprandial 5-HT levels are elevated in platelet-poor plasma tests from IBS-D [28-30] or post-infectious IBS patients, but they have been reduced or unchanged in IBS-C. 


\section{IBS and mental illness}

IBS and its symptoms largely impact daily activities and body image and are a cause of worry to patients. IBS is usually related to disgrace, and patients are stigmatized as 'frequent fliers' or 'somatizers'. Cognitive behavior therapy (CBT) could be a psychological or 'talking' therapy, which can be significantly helpful for patients with IBS. Fifty to $90 \%$ of IBS patients have a co-existing psychological condition, reminiscent of anxiety or depression (Table 1). Researchers have found high levels of reported sexual and emotional abuse among patients with IBS. Somatization disorder (SD), a psychiatric disorder has a prevalence of around $25 \%$ in patients with IBS, compared with around $1 \%$ among the overall population [31].

\section{Treatment of IBS}

\section{Conventional method}

Drugs are the most common treatment options for patients with gut disorders like IBS.

In cases of IBS-D and pain-predominant IBS, antispasmodics are used as the first-line treatments and include calcium channel blockers and neurokinin-type 2 receptor antagonists. Rifaximin is deemed to be the best second-line treatment for IBS-D. Rifaximin (RFX), is a non-absorbable antibiotic that inhibits protein synthesis and translation through binding to the beta subunit of bacterial DNAdependent RNA polymerase. RFX should be avoided in patients with hepatic impairment and in the case of pregnant women, this medication should be taken with caution due to the potential hazards to the fetus. For patients with IBS$\mathrm{C}$, besides fiber and laxatives, the most plausible option as a second-line treatment is linaclotide (LIN) [32]. Caution should be taken in pregnant women as it showed severe maternal toxicity in animal studies. Administration of LIN is not affected by renal or hepatic impairment as it is metabolized within GI-tract. Thus, laxatives should be chosen wisely and used with caution.

Ondansetron (OND) helps in relieving stool frequency, stool urgency, colonic transit time, and stool consistency. It is proved to have lower efficacy with disease progression; hence, it is only suitable for IBS with mild diarrhea. However, most of the OND treated patients experience constipation followed by headache, rectal bleeding, abdominal pain and backache.

As with other drugs for IBS-D, constipation and nausea are the first common side effects among patients treated by eluxadoline tablets. Patients without gallbladder tend to have sphincter of Oddi spasm (SOS) and pancreatitis. Eluxadoline should be avoided in patients with any stage of hepatic impairment as the plasma concentration made a 16-fold and 4-fold rise in severe and mild/moderate cases.

\section{Alternative/ complementary treatment}

Besides the conventional use of drugs to treat IBS, studies have also focused on many alternative treatments.

For instance, meditation was recently linked with an increase in dopamine levels. A study by Perreau-Linck and colleagues was among the first to show that self-induced changes in mood can affect one's serotonin production.

Another approach used in elevating serotonin levels is exposure to bright light.

In a study that assessed measurements of the serotonin metabolite 5-hydroxyindoleacetic acid (5-HIAA) in the venous outflow from the brain, a direct relation was observed between the duration of bright sunlight and the rate of serotonin synthesis. Similarly, serotonin levels are higher in the post-mortem brain of humans who died during summers, as compared to those who died during winters. In rats, the highest serotonin levels are observed during the light part of the light-dark cycle. In humans, the effect of tryptophan deficiency on the mood of healthy individuals was seen to be highly diminished under bright light, as opposed to dim light.

Exercise is also believed to increase serotonin function in the brain. Major studies in this matter were initiated under the hypothesis that the fatigue caused by exercise leads to increased plasma tryptophan and diminished levels of branched-chain amino acids (BCAAs) leucine, isoleucine, and valine This causes a significant increase in tryptophan availability as BCCAs can hinder tryptophan transport to the brain.

Post and colleagues assessed the biogenic amine metabolites in cerebrospinal fluid (CSF) of clinically

Table 1 IBS Patients with co-existing Mental illness studies

\begin{tabular}{|c|c|c|}
\hline Study & Number of Patients & Percentage of participants with psychological illness \\
\hline Blanchard et al (2007) & 210 & $\begin{array}{l}\text { 66.6\% (DSM-IV Axis } \\
\text { type-1 disorder) }\end{array}$ \\
\hline Kennedy et al (2005) & 149 & 43\% (Any psychological disorder in the past year) \\
\hline Payne and Blanchard (1995) & 34 & $\begin{array}{l}\text { 85\% (DSM-IV Axis } \\
\text { type-1 disorder) }\end{array}$ \\
\hline Tkachuk et al (2003) & 28 & 68\% (DSM-IV Axis type-1 disorder) \\
\hline
\end{tabular}

Deficiency of serotonin is common in IBS and as well as in many mental disorders. Many studies were done to study the existence of mental illness in IBS patients, here are enlisted some of the studies with the percentage of IBS patients with psychological illness [31] 
depressed patients before and after an elevation in their physical activity [33].

Patrick and Ames in 2015, studied the effects of aerobic exercise on brain serotonin levels. Exercise has the potential to increase tryptophan's chances of crossing the blood-brain barrier by muscular- uptake of competitive amino acids [34].

Regular exercise (30 min of swimming daily, 4 weeks) was seen to increase serotonin metabolism and production in the brainstem and cerebral cortex but decrease hippocampal serotonin levels.

In another study, the introduction of a low-to-moderate intensity exercise regime significantly improved IBS symptoms and this improvement remained considerable even 60 days post-training. However, signs of inflammation, oxidative stress, antioxidants, and other IBS symptoms were observed 8 weeks post-training. This led to the conclusion that a regular exercise routine is essential to conserve the benefits of exercise training.

Another well-known factor is diet. Foods that are rich in tryptophan are often believed to be associated with elevated serotonin levels. Since the early 1970s, nutritional research developments show that brain function is influenced by the availability of various nutrients in the diet. In the mid-1970s, Gessa et al. demonstrated that acute administration of a mixture of essential amino acids lacking Tryptophan (Trp-free mixture) produced a specific and long-lasting reduction of brain tryptophan and serotonin levels in rats [35].

Administration of this Trp-free amino acid mixture in rats produced a sharp drop in the concentration of serum tryptophan associated with a decrease in brain tryptophan, serotonin (5-HT), and 5-hydroxyindoleacetic acid (5-HIAA) levels in rats.

Ingestion of only proteins diminishes rat brain Tryptophan and 5-HT because all of the amino acids compete with tryptophan for transportation across the bloodbrain barrier. Conversely, carbohydrate consumption increases Trp and 5-HT levels in the brain as ingestion of carbohydrates increases blood insulin levels which in turn increases the uptake of branched-chain amino acids into muscles, thus decreases their plasmic concentration and competition at the blood-brain barrier.

A minor component of milk, $\alpha$-Lactalbumin, contains relatively more tryptophan than most proteins. In small quantities, the ingestion of $\alpha$-lactalbumin is seen to improve mood and cognition under certain circumstances, probably owing to elevated serotonin [36].

Dietary fibre is a safe and cheap way to improve IBS. As an example, bran is proved to be a natural bulking agent [37].

Peppermint oil is a common remedy for IBS and abdominal pain. It counters spasmodic movements by the transport of calcium ions across the cell membrane.
Techniques like Acupuncture and Colon Hydroscopy are also considered to help relieve abdominal distress. It has been indicated that several acupoints have distinguished effects on D-IBS, C-IBS, and abdominal irritation. It is known to exhibit certain gut responses that lead to inhibited acid output, reduced rectal hypersensitivity, and normalized motility. However, this effect is not always observed. Nevertheless, the National Institute for Health and Care Excellence (NICE) guidelines do promote the use of acupuncture to treat IBS.

Colon hydrotherapy (CHT) is a minimal access technique widely adopted to treat bowel inconsistencies. However, several side effects such as perforation, rectal bleeding, and pelvic abscess have been reported [38].

\section{Discussion}

The relationship between Serotonin and Gut has been stated in various research papers including various Gutrelated disorders like Irritable Bowel Syndrome (IBS) and their treatments along with detailed information of Serotonin-rich drugs to improve bodily functions but most of these studies include data based on populations of the countries in the west. Through this review paper, we have tried to discuss such disorders in the context of India's population and dietary routines including food items commonly consumed in different regions of India along with their tryptophan content and hence formulated an ideal diet (as per the data) which in the future, can be introduced to various IBS patients to check its effectiveness in improving their condition.

\section{Serotonin and diet}

A considerable amount of studies associate depleting serotonin levels with a dietary tryptophan deficiency. These studies also show that changes in plasma tryptophan influence brain tryptophan and thus, 5-HT concentrations. One such study on rats, at the Institute of Pharmacology and Nutritional Physiology, University of Cagliari, proved that a substantial decline in serum and brain tryptophan levels is followed by a decrease in 5-HT and 5-hydroxyindoleacetic acid (5-HIM), within 2 hours of consuming a tryptophan deficient diet [39]. It was also found that serotonin levels were increased when insulin was ejected into the body. The fatty acid, carbohydrate, protein components of the diet are believed to be responsible for a hike in insulin secretion; which in turn, increases plasma tryptophan levels. The elevation in plasma tryptophan, due to carbohydrates also elicits a simultaneous increase in brain tryptophan, thus raising the brain serotonin concentration [40]. However, a hypercaloric, high-fat-high-sugar diet is seen to significantly decrease SERT-binding by about 30\% [41] Thus, diets like the ketogenic diet (KD), which is a lowcarbohydrate, high-fat, is shown to affect concentrations of norepinephrine, dopamine, and serotonin, which in 
turn are proven to modulate seizure susceptibility in many animal models [40]. Such snacking-centric diets can therefore alter the serotonergic system and increase obesity risks.

This relationship between brain-serotonin and diet can also prove to be clinically important. Food items that are known to raise 5-HT levels, can be fed to patients to modulate brain outputs, associated with serotonergic neurons. Drug-efficacy for serotonin-receptor interactions may also be enhanced using this knowledge. Alternatively, the effectiveness of 5-HT blocking drugs can also be increased by the administration of tryptophandeficient diets [42].

It has been well established that a tryptophan-rich and FODMAP-low diet can aid in alleviating the symptoms of IBS. However, such dietary intervention has mostly been hypothesized for a western diet. In this review, we have discussed a diet based on the daily food intake of an average Indian individual. The daily L-tryptophan requirement for a normal human is $900-1000 \mathrm{mg}$ [43].

The diet of an IBS patient should be developed, keeping in mind the following aspects-

1. Water-soluble fiber- Dietary fiber increases stool bulk by stimulating colonic mucosa. However, consuming water-insoluble fiber, like bran, may further cause abnormal bloating and intestinal discomfort whereas water-soluble fiber like psyllium often aids in relieving symptoms of GI tract disorders [44].
2. Low fat- Patients with IBS are often subjected to gas retention (bloating), nausea, and distension caused by the intraluminal fat in the small intestine. They exhibit abnormal lipid dependent motor dysfunction and increased rectal hypersensitivity. Thus, few patients associate IBS with fat-intake. However, regular differences in dietary fat consumption levels have not been found between sound individuals and IBS patients [45].

3. Gluten-free- Gluten is a mixture of proteins- gliadin and glutenin. It increases intestinal permeability by changing the function of the mucosal barrier. A gluten-free diet would ultimately lead to decreased permeability and reduced bowel frequency in IBS-D patients. This would also cause a reduced intake of FODMAPS which would ultimately aid in relieving IBS symptoms.

4. Low FODMAPs- FODMAPs (Fermented Oligosaccharides, Disaccharides, Monosaccharides, and Polyols), are a group of short-chain carbohydrates that are digested and absorbed poorly in the GI tract. Some examples include fructose, raffinose, nystose, and kestose. A low FODMAP diet has been effectively proven to be effective against IBS symptoms in numerous clinical trials. However, studies are still required for the determination of FODMAP contents in common Indian foods and the tolerance levels in an Asian setting.

5. Tryptophan-rich diet- Elevated serotonin levels are often associated with tryptophan-rich food

Table 2 Tryptophan Content in food items with low FODMAP

\begin{tabular}{llllll}
\hline $\begin{array}{l}\text { Food items } \\
\text { with High } \\
\text { FODMAP }\end{array}$ & $\begin{array}{l}\text { Tryptophan Content } \\
\mathbf{( g )}(\mathbf{p e r} \mathbf{1 0 0} \mathbf{g} \text { of food } \\
\text { item) }\end{array}$ & $\begin{array}{l}\text { Water-Soluble Dietary } \\
\text { Fiber (g) (per } \mathbf{1 0 0} \mathbf{g} \text { of } \\
\text { food item) }\end{array}$ & $\begin{array}{l}\text { Food items } \\
\text { with Low } \\
\text { FODMAP }\end{array}$ & $\begin{array}{l}\text { Tryptophan Content } \\
\text { (g) (per 100 g of food } \\
\text { item) }\end{array}$ & $\begin{array}{l}\text { Water-Soluble Dietary } \\
\text { Fiber (g) (per 100 g of } \\
\text { food item) }\end{array}$ \\
\hline Apple & 0.0030 & 2.44 & Banana & 0.0118 & 1.04 \\
Mango & 0.0056 & 1.10 & Orange & 0.0003 & 0.56 \\
Wheat & 0.1168 & 4.67 & Maize & 0.0632 & 0.94 \\
Barley & 0.2080 & 3.01 & Rice & 0.0860 & 0.82 \\
Rye & 0.1080 & 15.1 & Ragi & 0.0664 & 1.67 \\
Cabbage & 0.0230 & 2.47 & Brinjal & 0.0156 & 1.20 \\
Cauliflower & 0.0291 & 2.51 & Capsicum & 0.0124 & 0.73 \\
Cashew & 0.2226 & 3.30 & Almond & 0.1851 & 2.52 \\
Pistachio & 0.2811 & 10.3 & Walnut & 0.1622 & 0.65 \\
Cheese & 0.2002 & 0.00 & Yogurt & 0.1550 & 0.00 \\
Milk & 0.0452 & 0.00 & Oats & 0.1785 & 3.81 \\
Honey & 0.0042 & 0.23 & Kidney Beans & 0.2790 & 2.62 \\
Mushroom & 0.0356 & 1.02 & Bitter Gourd & 0.0204 & 3.10 \\
Beetroot & 0.0142 & 2.84 & Lady Finger & 0.0093 & 1.33
\end{tabular}

Along with taking the appropriate amount of Tryptophan, a low FODMAPs (Fermented Oligosaccharides, Disaccharides, Monosaccharides, And Polyols) can also help in improving the condition. A diet with poorly adsorbed FODMAPs is considered as an effective strategy for symptom control in patients with IBS. A reason that contributes to poor absorption of FODMAPs includes the absence of luminal enzymes capable of hydrolyzing glycosidic bonds present in complex carbohydrates and the absence or low activity of brush border enzymes such as GLUT-2 and GLUT-5 [47] 
Table 3 An example of Indian ideal diet for IBS patient

\begin{tabular}{|c|c|c|c|c|}
\hline Breakfast & Mid-Snack & Lunch & Mid-Snack & Dinner \\
\hline $\begin{array}{l}1 \text { bowl of Greek } \\
\text { Yogurt OatMeal } \\
1 \text { cup Oats }(0.1785 \mathrm{~g} \\
\text { Trp and } 3.81 \mathrm{~g} \text { DF) }+1 \text { Banana } \\
(0.0139 \mathrm{~g} \text { Trp and } 1.227 \mathrm{~g} \text { DF) + } \\
1 \text { cup water }+1 / 4 \text { cup Greek } \\
\text { yogurt ( } 0.0949 \mathrm{~g} \text { Trp and } 0 \mathrm{~g} \text { DF) }\end{array}$ & $\begin{array}{l}1 \text { bowl Nuts } \\
1 / 2 \text { cup } \\
\text { Almonds } \\
(0.0925 \mathrm{~g} \text { Trp } \\
\text { and } 1.26 \mathrm{~g} \text { DF) } \\
+ \\
1 / 2 \text { cup Walnuts } \\
(0.1054 \mathrm{~g} \text { Trp } \\
\text { and } 0.42 \mathrm{~g} \text { DF) }\end{array}$ & $\begin{array}{l}\text { Rajma Chawal (Kidney } \\
\text { Beans Curry + Rice) } \\
1 \text { serving Rice } \\
(0.1075 \mathrm{~g} \text { Trp and } 1.025 \mathrm{~g} \\
\text { DF) }+1 \text { cup Rajma }(0.1743 \mathrm{~g} \\
\text { Trp and } 1.63 \mathrm{~g} \text { DF) }\end{array}$ & $\begin{array}{l}2 \text { Medium Sized } \\
\text { Oranges }(0.00084 \mathrm{~g} \\
\text { Trp and } 0.784 \mathrm{~g} \text { DF) }\end{array}$ & $\begin{array}{l}\text { 3-4 Roti (Indian flat Bread) using } \\
\text { Multigrain Flour } \\
1 / 2 \text { cup Maida }+1 / 2 \text { cup Ragi }(0.1031 \mathrm{~g} \text { Trp } \\
\text { and } 2.02 \mathrm{~g} \text { DF) With } 1 \text { Cup Capsicum } \\
\text { Curry }(0.0217 \mathrm{~g} \text { Trp and } 1.27 \mathrm{~g} \text { DF) } \\
\text { Or, } \\
\mathbf{1} \text { Cup Bhindi Fry (Fried Okra) }(0.01729 \mathrm{~g} \\
\text { Trp and } 2.47 \mathrm{~g} \text { DF) } \\
\text { Or, } \\
\mathbf{1} \text { Cup Karela (Bitter Gourd Curry) } \\
\text { (0.0252 g Trp and } 3.844 \mathrm{~g} \text { DF) }\end{array}$ \\
\hline $\begin{array}{l}\text { Total }=0.2846 \mathrm{~g} \text { Trp and } \\
5.037 \mathrm{~g} \mathrm{DF}\end{array}$ & $\begin{array}{l}\text { Total }=0.1979 \\
\text { g Trp and } \\
1.68 \mathrm{~g} \mathrm{DF}\end{array}$ & $\begin{array}{l}\text { Total }=0.3879 \mathrm{~g} \text { Trp and } \\
2.655 \mathrm{~g} \mathrm{DF}\end{array}$ & $\begin{array}{l}\text { Total }=0.2846 \mathrm{~g} \text { Trp } \\
\text { and } 5.037 \mathrm{~g} \mathrm{DF}\end{array}$ & Total $=0.125 \mathrm{~g} \operatorname{Trp}($ Avg.) and $4 \mathrm{~g} \mathrm{DF}$ \\
\hline
\end{tabular}

*DF- Dietary Fiber, Trp- Tryptophan [45]

consumption. There have been studies that observed a drop in 5- HT serum concentration and reduction in brain-tryptophan, upon administration of a tryptophan-free amino acid mixture.

Diversity in eating habits, patterns, food items, occurs when we move from north to south or east to west India, due to cultural differences, local vegetation, different climatic conditions, social issues, religious beliefs, resources availability, differences in abiotic factors like soil, etc. Many food items, predominant in the Indian diet, possess these qualities and have been listed in (Table 2) [46].

By contrast, about three-fourths of the population in the United States has an eating pattern that is low in vegetables, fruits, dairy, and oils. More than half of the population is exceeding total grain, total protein, saturated fats, sodium, and added sugar recommendations revealing an eating pattern too high in calories.

Along with taking the appropriate amount of Tryptophan, a low FODMAPs (Fermented Oligosaccharides, Disaccharides, Monosaccharides, And Polyols) can also help in improving the condition. A diet with poorly adsorbed FODMAPs is considered as an effective strategy for symptom control in patients with IBS. A reason that contributes to poor absorption of FODMAPs includes the absence of luminal enzymes capable of hydrolyzing glycosidic bonds present in complex carbohydrates and the absence or low activity of brush border enzymes such as GLUT-2 and GLUT-5 [46].

As an example, the above data has been used to formulate an ideal diet for IBS patients in (Table 3) which will fulfill the daily tryptophan requirements (900-1000 $\mathrm{mg})$ and dietary fiber requirements(15-20 g) while keeping the low and high FODMAPs food items in balance.

\section{Conclusion and limitations}

The interconnection of all bodily functions is evident when we examine the 'Happy Hormone'- serotonin and trace its functioning from acting as a neurotransmitter to playing an important role in the development of gastrointestinal disorders like Irritable bowel syndrome. Our dietary intake plays a key role in the regulation of IBS, and this information has been utilized to narrow down on food items in the Indian diet which possess all five qualities of being gluten-free, low in fat, low in FODMAP content, rich in tryptophan, and possessing water-soluble fibers.

A limitation of this study would be the absence of a professionally prescribed diet. The regime mentioned in the results of this review is concluded based on readings and analysis of existing literature and is derived from previously-concluded trials.

\section{Abbreviations}

5-HT: 5-Hydroxytryptamine; IBS: Irritable Bowel Syndrome;

EC: Enterochromaffin; TPH1: Tryptophan hydroxylase-1; CBT: Cognitive Behavior Therapy; FODMAP: Fermented Oligosaccharides, Disaccharides, Monosaccharides, And Polyols; CHT: Colon HydroTherapy; GLUT-1: Glucose Transporter-1; GLUT-2: Glucose Transporter-2; GI: Gastrointestinal; IBSD: Irritable Bowel Syndrome-Diarrhea; IBS-C: Irritable Bowel SyndromeConstipation; IBS-M: Irritable Bowel Syndrome-Mixed type; DSM: Diagnostic and Statistical Manual of mental disorders

\section{Acknowledgments}

We would like to express our special thanks and gratitude to the Department of Biochemistry, Shaheed Rajguru College of Applied Sciences for Women, University of Delhi, for providing us with valuable opportunities and shaping us into able individuals.

\section{Declarations}

Data sharing not applicable to this article as no datasets were generated or analyzed during the current study.

\section{Authors' contributions}

The review article was envisaged by Khushi Bruta, Vanshika, Kishnoor Bhasin, Dr. Bhawana and all are equal contributors in drafting the manuscript and performing the literature search. Dr. Bhawana also guided us throughout the process and helped us bridge our idea across to a wider community. The authors read and approved the final manuscript.

\section{Funding}

No funding source is available.

Ethics approval and consent to participate Not applicable. 


\section{Consent for publication}

Not applicable.

\section{Competing interests}

The authors declare that they have no competing interests.

Received: 27 October 2020 Accepted: 15 December 2020 Published online: 05 January 2021

\section{References}

1. Kendig DM, Grider JR. Serotonin and colonic motility. Neurogastroenterol Motil. 2015;27(7):899-905.

2. Kadowaki M, Wang XO, Shimatani H, Yoneda S, Takaki M. 5-HT4 receptor enhances the propulsive power of the peristaltic reflex in the rat distal colon. Auton Neurosci. 2002;99(1):62-5.

3. Martin AM, Young RL, Leong L, Rogers GB, Spencer NJ, Jessup CF, et al. The diverse metabolic roles of peripheral serotonin. Endocrinology. 2017;158(5): 1049-63.

4. Budhoo MR, Harris RP, Kellum JM. 5-Hydroxytryptamine-induced cltransport is mediated by 5-HT3 and 5-HT4 receptors in the rat distal colon. Eur J Pharmacol. 1996;298(2):137-44.

5. Burleigh DE, Borman RA. Short-circuit current responses to 5hydroxytryptamine in human ileal mucosa are mediated by a 5-HT4 receptor. Eur J Pharmacol. 1993;241(1):125-8.

6. Siriwardena A, Kellum JM Jr. A 5-HT2 receptor mediates serotonin-induced electrolyte transport in rat left colon. J Surg Res. 1993;55(3):323-9.

7. Mohammad-Zadeh LF, Moses L, Gwaltney-Brant SM. Serotonin: a review. J Vet Pharmacol Ther. 2008;31(3):187-99.

8. Imada-Shirakata Y, Kotera T, Ueda S, Okuma M. Serotonin activates electrolyte transport via 5-HT2AReceptor in rat colonic crypt cells. Biochem Biophys Res Commun. 1997;230(2):437-41.

9. Tuo BG, Isenberg Jl. Effect of 5-hydroxytryptamine on duodenal mucosal bicarbonate secretion in mice. Gastroenterology. 2003;125(3):805-14.

10. Tuo BG, Sellers Z, Paulus P, Barrett KE, Isenberg J. 5-HT induces duodenal mucosal bicarbonate secretion via CAMP-and Ca2+-dependent signaling pathways and 5-HT4 receptors in mice. Am J Physiol-Gastrointest Liver Physiol. 2004;286(3):G444-51.

11. Cho HJ, Callaghan B, Bron R, Bravo DM, Furness JB. Identification of enteroendocrine cells that express TRPA1 channels in the mouse intestine. Cell Tissue Res. 2014;356(1):77-82.

12. Watanabe H, Akasaka D, Ogasawara H, Sato K, Miyake M, Saito K, et al. Peripheral serotonin enhances lipid metabolism by accelerating bile acid turnover. Endocrinology. 2010;151(10):4776-86.

13. Raybould HE, Glatzle J, Robin C, Meyer JH, Phan T, Wong H, et al. Expression of 5-HT3 receptors by extrinsic duodenal afferents contribute to intestinal inhibition of gastric emptying. Am J Physiol-Gastrointest Liver Physiol. 2003; 284(3):G367-72.

14. LePard KJ, Stephens RL. Serotonin inhibits gastric acid secretion through a 5-hydroxytryptamine1-like receptor in the rat. J Pharmacol Exp Ther. 1994; 270(3):1139-44.

15. Wøjdemann M, Wettergren A, Hartmann B, Holst JJ. Glucagon-like peptide-2 inhibits centrally induced antral motility in pigs. Scand J Gastroenterol. 1998; 33(8):828-32.

16. Wøjdemann M, Wettergren A, Hartmann B, Hilsted L, Holst JJ. Inhibition of sham feeding-stimulated human gastric acid secretion by glucagon-like peptide-2. J Clin Endocrinol Metabol. 1999;84(7):2513-7.

17. Jenkins TA, Nguyen JC, Polglaze KE, Bertrand PP. Influence of tryptophan and serotonin on mood and cognition with a possible role of the gut-brain axis. Nutrients. 2016;8(1):56.

18. Margolis KG, Stevanovic K, Li Z, Yang QM, Oravecz T, Zambrowicz B, et al. Pharmacological reduction of mucosal but not neuronal serotonin opposes inflammation in mouse intestine. Gut. 2014;63(6):928-37.

19. Zelkas L, Raghupathi R, Lumsden AL, Martin AM, Sun E, Spencer NJ, et al. Serotonin-secreting enteroendocrine cells respond via diverse mechanisms to acute and chronic changes in glucose availability. Nutr Metab. 2015;12(1):1-9.

20. Manocha M, Khan WI. Serotonin and Gl disorders: an update on clinical and experimental studies. Clin Transl Gastroenterol. 2012;3(4):e13.

21. Fitzgerald P, Cassidy Eugene M, Clarke G, Scully P, Barry S, Quigley Eamonn MM, et al. Tryptophan catabolism in females with irritable bowel syndrome: relationship to interferon-gamma, severity of symptoms and psychiatric comorbidity. Neurogastroenterol Motil. 2008;20(12):1291-7.

22. Clarke G, Fitzgerald P, Cryan JF, Cassidy EM, Quigley EM, Dinan TG. Tryptophan degradation in irritable bowel syndrome: evidence of indoleamine 2, 3-dioxygenase activation in a male cohort. BMC Gastroenterol. 2009:9(1):1-7.

23. Coates MD, Mahoney CR, Linden DR, Sampson JE, Chen J, Blaszyk H, et al. Molecular defects in mucosal serotonin content and decreased serotonin reuptake transporter in ulcerative colitis and irritable bowel syndrome. Gastroenterology. 2004;126(7):1657-64.

24. Tack J, Broekaert D, Corsetti M, Fischler B, Janssens J. Influence of acute serotonin reuptake inhibition on colonic sensorimotor function in man. Aliment Pharmacol Ther. 2006;23(2):265-74.

25. Coates MD, Johnson AC, Greenwood-van Meerveld B, Mawe GM. Effects of serotonin transporter inhibition on gastrointestinal motility and colonic sensitivity in the mouse. Neurogastroenterol Motil. 2006;18(6):464-71.

26. Sikander A, Rana SV, Sinha SK, Prasad KK, Arora SK, Sharma SK, et al. Serotonin transporter promoter variant: analysis in Indian IBS patients and control population. J Clin Gastroenterol. 2009:43(10):957-61.

27. Houghton LA, Atkinson W, Whitaker RP, Whorwell PJ, Rimmer MJ. Increased platelet depleted plasma 5-hydroxytryptamine concentration following meal ingestion in symptomatic female subjects with diarrhoea predominant irritable bowel syndrome. Gut. 2003;52(5):663-70.

28. Atkinson W, Lockhart S, Whorwell PJ, Keevil B, Houghton LA. Altered 5hydroxytryptamine signaling in patients with constipation-and diarrheapredominant irritable bowel syndrome. Gastroenterology. 2006;130(1):34-43.

29. Dunlop SP, Coleman NS, Blackshaw E, Perkins AC, Singh G, Marsden CA, et al. Abnormalities of 5-hydroxytryptamine metabolism in irritable bowel syndrome. Clin Gastroenterol Hepatol. 2005;3(4):349-57.

30. David DA. Irritable bowel syndrome: psychological comorbidities and cognitive behavioural therapy. A review of the literature. Gastrointest Nurs. 2012;10(10):44-50

31. Mousavi T, Nikfar S, Abdollahi M. An update on efficacy and safety considerations for the latest drugs used to treat irritable bowel syndrome. Expert Opin Drug Metab Toxicol. 2020;16(7):583-604.

32. Young SN. How to increase serotonin in the human brain without drugs. J Psych Neurosci. 2007;32(6):394.

33. Maleki BH, Tartibian B, Mooren FC, FitzGerald LZ, Krüger K, Chehrazi M, et al. Low-to-moderate intensity aerobic exercise training modulates irritable bowel syndrome through antioxidative and inflammatory mechanisms in women: results of a randomized controlled trial. Cytokine. 2018;102:18-25.

34. Fadda F. Tryptophan-free diets: a physiological tool to study brain serotonin function. Physiology. 2000;15(5):260-4.

35. Chang FY, Lu CL. Treatment of irritable bowel syndrome using complementary and alternative medicine. J Chin Med Assoc. 2009;72(6): 294-300.

36. Heijnen S, Hommel B, Kibele A, Colzato LS. Neuromodulation of aerobic exercise—a review. Front Psychol. 2016;6:1890.

37. Thompson WG. Irritable bowel syndrome: a management strategy. Best Pract Res Clin Gastroenterol. 1999;13(3):453-60.

38. Richard DM, Dawes MA, Mathias CW, Acheson A, Hill-Kapturczak N, Dougherty DM. L-tryptophan: basic metabolic functions, behavioral research and therapeutic indications. Int J Tryptophan Res. 2009;2: IJTR-S2129.

39. Biggio G, Fadda F, Fanni P, Tagliamonte A, Gessa GL. Rapid depletion of serum tryptophan, brain tryptophan, serotonin and 5-hydroxyindoleacetic acid by a tryptophan-free diet. Life Sci. 1974;14(7):1321-9.

40. Fernstrom JD, Wurtman RJ. Brain serotonin content: increase following ingestion of carbohydrate diet. Science. 1971;174(4013):1023-5.

41. Koopman KE, Booij J, Fliers E, Serlie MJ, La Fleur SE. Diet-induced changes in the lean brain: hypercaloric high-fat-high-sugar snacking decreases serotonin transporters in the human hypothalamic region. Mol Metab. 2013; 2(4):417-22.

42. Fernstrom JD. Modification of brain serotonin by the diet. Annu Rev Med. 1974;25(1):1-8.

43. El-Salhy M, Ystad SO, Mazzawi T, Gundersen D. Dietary fiber in irritable bowel syndrome. Int J Mol Med. 2017;40(3):607-13.

44. Mullie P, Godderis L, Clarys P. Determinants and nutritional implications associated with low-fat food consumption. Appetite. 2012;58(1):34-8. 
45. Longvah T, Anantan I, Bhaskarachary K, Venkaiah K, Longvah T. Indian food composition tables. Hyderabad: National Institute of Nutrition, Indian Council of Medical Research; 2017.

46. Dhingra D, Michael M, Rajput H, Patil RT. Dietary fibre in foods: a review. J Food Sci Technol. 2012;49(3):255-66.

47. Devinder Dhingra, Mona Michael, Hradesh Rajput, R. T. Patil Dietary fibre in foods: a review. J Food Sci Tech. 2012;(3):255-66.

\section{Publisher's Note}

Springer Nature remains neutral with regard to jurisdictional claims in published maps and institutional affiliations.

Ready to submit your research? Choose BMC and benefit from:

- fast, convenient online submission

- thorough peer review by experienced researchers in your field

- rapid publication on acceptance

- support for research data, including large and complex data types

- gold Open Access which fosters wider collaboration and increased citations

- maximum visibility for your research: over $100 \mathrm{M}$ website views per year

At BMC, research is always in progress.

Learn more biomedcentral.com/submissions 